\title{
DA TRADIÇÃO MILENAR À CONTEMPORANEIDADE: SIGNIFICADOS DA CERIMÔNIA DO CHÁ JAPONESA ${ }^{1}$ FROM THE ANCIENT TRADITION TO THE CONTEMPORANEITY: MEANINGS OF THE NIPONIC TEA CEREMONY IN BRAZIL
}

\author{
Fernanda Guarnieri ${ }^{2}$ \\ Nôga Simões de Arruda Corrêa da Silva ${ }^{3}$ \\ Olga Maria Coutinho Pépece ${ }^{4}$
}

É possível compreender os significados da Cerimônia do Chá Japonesa no século XXI por meio da Teoria de estudos de cultura e consumo com foco no consumo ritualístico. Ao identificar os significados desse ritual desde a tradição milenar, é possível compreender as influências culturais e de consumo de povos nipônicos na cultura brasileira. Foi realizada pesquisa qualitativa com entrevistas e observação participante em Cerimônias do Chá. Os resultados apontaram que a Cerimônia do Chá é um ritual de troca e que os seus significados se mantêm fiéis à tradição japonesa, atrelados à harmonia, ao respeito, à pureza e à tranquilidade. Além disso, as Cerimônias do Chá realizadas no Brasil despertam o interesse de japoneses residentes atualmente no Japão, que buscam nestas cerimônias uma forma de reviver as práticas das tradições japonesas do período milenar.

Palavras-chave: Rituais de Consumo. Cerimônia do Chá. Consumo Transcultural. Significados de Consumo. Cultura japonesa.

1 Artigo submetido em 26/11/2019 e aprovado em 08/04/2020.

2 Doutoranda e Mestre em Administração pela Universidade Estadual de Maringá, Maringá, Brasil; fernandamguarnieri@gmail.com (ORCID iD: https://orcid.org/0000-0001-5645-7657).

3 Mestre em Administração pela Universidade Estadual de Maringá, Maringá, Brasil; noga.simoes@ gmail.com (ORCID iD: https://orcid.org/0000-0002-2799-5058).

4 Professora Associada do Departamento de Administração da Universidade Estadual de Maringá, Maringá, Brasil; Doutora em Administração pela Universidade Federal do Paraná; opepece@gmail. com (ORCID iD: https://orcid.org/0000-0002-9155-9285). 
Understanding the meanings of the Japanese Tea Ceremony in the 21 st Century is important for consumer studies. By identifying meanings of this ritual since ancient tradition, it is possible to understand how cultural and consumption influences of Japanese ethnic groups that immigrated to Brazil. Qualitative research was carried out with interviews and participant observation in Tea Ceremonies. The results pointed out that the Tea Ceremony is a ritual of exchange and that its meanings remain faithful to the Japanese tradition, tied to harmony, respect, purity and tranquility; awakening even the interest of Japanese citizens who reside in Japan, seeking in Brazil a way to revive the practices of Japanese traditions in the millennial period.

Keywords: Consumption Rituals. Tea Ceremony. Transcultural Consumption. Meanings of Consumption. Japanese culture.

\section{Introdução}

O ritual, conforme definido por McCracken (2007, p. 108), “é compreendido como uma ação social cultivada para a manipulação do significado cultural, como comunicação e categorização individual e coletiva", afirmando, exaltando ou revisando símbolos e significados da ordem cultural. A ausência de rituais consiste em viver sem significados claros e, provavelmente, sem memórias, portanto os rituais possuem relevância histórica (DOUGLAS; ISHERWOOD, 2004) e de organização e manutenção de valores da sociedade.

A compreensão sobre os rituais de consumo repousa em aspectos presentes na sociedade e quando investigada por lentes da cultura de consumo (CUPOLLILO; CASOTTI; CAMPOS, 2014), permite a apreensão dos significados simbólicos que cercam os ambientes de mercado, assim como as influências culturais manifestadas por meio dos comportamentos de consumo ritualizados.

As práticas culturais e rituais, devido a sua importância para as comunidades de origem, são ensinadas de geração em geração e acompanham os indivíduos quando esses imigram para diferentes locais (CUPOLLILO; CASOTTI; CAMPOS, 2014). Quando a imigração é de muitos indivíduos, a realização dessas práticas extrapola o âmbito familiar e ganha espaço público, influenciando e envolvendo inclusive a cultura do local de imigração. Como exemplo, é possível citar a comunidade alemã que reside no estado de Santa Catarina e realiza anualmente a Oktoberfest, uma festa inspirada na festa homônima realizada em Munique, desde o século XIX, para desfrutar o consumo de um produto bastante típico na Alemanha, a cerveja. A Oktoberfest da cidade de Blumenau teve início há 35 anos (A FESTA, 2019) e atualmente atrai pessoas de todo o Brasil, representando importante contribuição econômica para o município ${ }^{5}$. Outro exemplo de imigrantes que ingressaram no Brasil com grande número de famílias é o caso da comunidade japonesa presente em diversas regiões do Brasil e concentradas nos estados de São Paulo e do Paraná. Dentre as tradições culturais dos povos japoneses,

5 No ano de 2018 o público total da Oktoberfest somou 592.291 visitantes segundo Lima (2019). 
destaca-se a Cerimônia do Chá. Desde o início da imigração japonesa para o Brasil, esta Cerimônia assumiu importância para os imigrantes ao permitir a manutenção da cultura de origem.

À vista disso, considerando a importância do conhecimento dos rituais de consumo para a compreensão das tradições culturais dos indivíduos imigrantes, buscou-se compreender os componentes rituais da Cerimônia do Chá, de tradição japonesa, no século XXI, no Brasil. É prudente ressaltar dois aspectos sobre o objetivo proposto no que tange aos imigrantes e no que diz respeito aos rituais. Primeiro, as tradições culturais se fazem importantes ao enfatizar os significados dos discursos culturais locais e de imigrantes (GOLDSTEIN-GIDONI, 2005). Segundo, conforme apontado por McCracken (2003), os rituais são de grande importância para a compreensão da dimensão simbólica do consumo, visto que as práticas rituais constituem o sistema de consumo e as práticas sociais dos consumidores. Conforme será apresentado mais adiante, foram investigados como objetivos específicos neste artigo os quatro componentes atrelados à experiência de rituais que têm como base Rook (2007), os quais são 1) o roteiro, 2) os artefatos, 3) a representação dos papéis e 4|) a plateia do ritual. Também foram objetivos deste artigo identificar os significados socioculturais e as contribuições do consumo da Cerimônia do Chá.

\section{Referencial teórico}

\subsection{Teoria de Cultura e Consumo}

A cultura é compreendida, conforme Hofstede (1997, p. 5), como a "programação coletiva da mente que distingue os membros de um grupo ou categoria de pessoas de outro". Em vista disso, "podemos pensar na cultura como personalidade de uma sociedade", resultado da acumulação de significados, rituais, normas e tradições compartilhados entre os membros de uma organização ou sociedade (SOLOMON, 2011, p. 568).

Luna e Gupta (2001) ressaltam que as manifestações culturais são reforçadas pelo comportamento de consumo que é influenciado pela cultura. O comportamento de consumo ocorre em consequência dos sistemas de valores culturais que um indivíduo apresenta em comum com grupos aos quais pertence. Esse comportamento pode ser identificado e adotado como uma cultura específica de uma população (LUNA; GUPTA, 2001). Para investigar esse tema, Casotti e Suarez (2016, p. 358) observam que "o Brasil é um contexto relevante por suas características históricas e sociais que constroem um caldeirão multicultural, de convivência e miscigenação de diferentes etnias".

Hofstede (1997), na mesma linha, destaca quatro manifestações culturais que influenciam o comportamento de consumo: valores, heróis, símbolos e rituais. Os valores remetem a uma crença norteadora de ações e julgamentos em determinadas situações. Os heróis referem-se àqueles indivíduos, vivos ou falecidos, reais ou imaginários, sendo valorizados e considerados como exemplos de comportamento 
(HOFSTEDE, 1997), que estão relacionados com o respeito e o compromisso em preservar tradições culturais (SCHWARTZ; SAGIE, 2000) consideradas relevantes por grupos sociais. Os símbolos representam uma categoria de processos e objetos que, juntos, constituem um significado que é específico de um grupo particular de indivíduos (HOFSTEDE, 1997).

Já os rituais, que serão mais bem compreendidos a seguir, remetem a um significado cultural, algo mais amplo englobando a cultura de um povo. No que tange aos principais conceitos atrelados aos rituais, Turner (1974/2005, p. 49) traz o conceito de ritual como um "comportamento formal prescrito por ocasiões determinadas por rotinas não tecnológicas e que tem referências em crenças e seres ou poderes místicos". Além disso, os rituais são constituídos por uma sequência de ações padronizadas com repetições periódicas, transmitindo "significados e dizem respeito ao uso de símbolos culturais" (TUNER, 1974/2005, p.49). Em linha com esse entendimento, os aspectos ritualísticos estão inseridos no que abrangem as teorias de cultura e consumo. Isso porque, conforme assinalado por Casotti e Suarez (2016, p. 355), tais teorias partem essencialmente dos "significados sociais, influências sócio-históricas e dinâmicas sociais que moldam as experiências do consumidor e suas identidades nos mais variados contextos da vida cotidiana".

\subsection{Rituais de consumo}

Os estudos relacionados aos rituais de consumo são oriundos de Levy (1959), que apresenta um enfoque para o valor simbólico presente no consumo, e do trabalho de Rook (2007). Rook e Levy (1983) perceberam a presença do tema rituais de consumo ao entenderem o comportamento ritual como meio de análise da interpretação dos significados simbólicos do consumo.

Rook (2007, p. 83) define ritual "como um tipo de atividade expressiva e simbólica construída de múltiplos comportamentos que se dão em uma sequência fixa e episódica e tendem a se repetir com o passar do tempo". Conforme o autor, a experiência do ritual está relacionada a quatro componentes: i) roteiro do ritual, que orienta o uso dos artefatos materiais e os papéis dos agentes no ritual; ii) artefatos rituais (alimentos e bebidas, diplomas, velas, dentre outros), os quais são utilizados em um contexto ritualístico comunicando mensagens simbólicas específicas que compõem o significado da experiência como um todo; iii) representação do(s) papel(éis) do ritual, que pode ser extensa, limitada, ou inexistente, passiva ou ativa, visto que a mídia de massa permite participar de uma variedade de rituais indiretamente e não como participante direto; iv) plateia do ritual, que pode ser uma plateia maior do que a das pessoas com papel específico na realização do ritual.

Além dos quatro componentes descritos por Rook (2007), o autor ainda destaca como característica essencial dos rituais a repetição, pois dela depende a perpetuação dessa manifestação cultural. Analisando diferentes tipos de rituais, autores como Van 
Gennep (1978) identificaram que esses podem ser classificados socialmente de acordo com seu objetivo principal. Assim, existem rituais de separação, como por exemplo, velórios; rituais de margem, que representam situações temporárias, como por exemplo, cerimônias de noviças que estão se candidatando à vida religiosa; e rituais de agregação, como é possível exemplificar nos casamentos. McCracken (2007) classifica os rituais de consumo e chega a quatro categorizações: i) rituais de troca, ii) rituais de posse, iii) rituais de arrumação e iv) rituais de despojamento. Os rituais de troca ocorrem em celebrações como Natal e aniversários, de forma que ocorre na escolha, na compra e na apresentação dos bens de consumo, sendo, por exemplo, o ato de presentear que é um ato de troca. No que diz respeito aos rituais de posse, despende-se tempo limpando, discutindo e refletindo sobre, mostrando ou mesmo fotografando as posses, na tentativa de extrair do objeto as qualidades que lhe foram conferidas (MCCRACKEN, 2007).

Nos rituais de arrumação, verifica-se que parte do significado extraído dos bens tem uma natureza perecível, de modo que o consumidor necessita extrair esse significado de suas posses de forma contínua, como por exemplo, limpando os bens para conservá-los. Quanto aos rituais de despojamento, há dois tipos. Um ocorre quando o indivíduo compra um bem que pertenceu a outro indivíduo e deseja deletar o significado associado ao proprietário anterior. O outro tipo acontece quando a pessoa está quase dispensando um bem e com isso busca apagar o significado que foi investido nesse bem (MCCRACKEN, 2007).

\subsection{Consumo e Cerimônia do Chá}

O consumo do chá como bebida surgiu na China durante os séculos I e II, na dinastia Han (HIROSE, 2010). Devido a sua preciosidade, o chá foi inicialmente utilizado como remédio até ser consumido por imperador, nobres e religiosos. Incorporado na China no século VI, transformou-se em bebida para consumo entre membros de comunidades religiosas e pela elite do século (BLEILER, 1963; HIROSE, 2010; BOIKO, 2011; JHUN, 2012; ANDERSON, 1987). Posteriormente, entre os séculos XI e XII, a doutrina Budista Zen, que surgiu no século VI, foi sendo difundida no Japão (BOIKO, 2011). Os monges consumiam o chá para permanecerem acordados durante a meditação noturna nos mosteiros. Com o passar do tempo, desenvolveram uma filosofia de vida em que encontrariam sua realização no Chado ou Cerimônia do chá (HIROSE, 2010).

A partir de sua difusão no Japão, as reuniões de chá tornaram-se uma forma de entretenimento, promovidas, inicialmente, como forma de identificar vários tipos de chá (JHUN, 2012). Segundo Boiko (2011), nesses encontros eram realizados concursos, que premiavam os mais experientes no preparo da bebida. Mas foi Murata Shuko que transformou essas reuniões na Cerimônia do Chá propriamente dita. Além disso, Shuko foi o primeiro mestre que valorizou a Cerimônia e adotou-a na cultura japonesa. O mestre passou a utilizar a caligrafia para a decoração para o tokonoma; criou novos utensílios e introduziu a estante para guardar os objetos da Cerimônia (daisu). Também desenvolveu 
as normas para regulamentação da Cerimônia no código de boas maneiras dos samurais (Bushido) e dos monges Zen durante as refeições, compreendendo a Cerimônia a partir de um estilo elegante e simples de expressão relacionada à vida do povo (HIROSE, 2010; ANDERSON, 1987).

Porém, é no período Momoyama, no século XVI, com Sen-no-Rikyu que a Cerimônia adota sua estrutura definitiva e forma mais desenvolvida, com o modelo chashitsu, ou Cabana de Chá, e seu jardim (BOIKO, 2011). Rikyu inseriu na Cerimônia algumas características, como: o local, que transmite a "simplicidade de uma cabana de camponeses, com seu telhado rústico e teto de bambu, janelas de treliça e paredes toscas; o jardim roji, uma das formas mais elevadas de arte (RAFACHO, 2007), que relembra uma paisagem de montanha e induz à meditação; e a decoração sóbria" (HIROSE, 2010, p. 96). Além das vestimentas utilizadas por aqueles que participavam das Cerimônias, como os quimonos (GREINER, 2015). Para o mestre Rikyu, segundo Hirose (2010), a Cerimônia deve ser pautada na harmonia $(\mathrm{Wa})$, no respeito $(\mathrm{Kei})$, na pureza $(\mathrm{Sei})$ e na tranquilidade $(\mathrm{Jaku})$, os seus princípios básicos.

Esse período de definição e desenvolvimento definitivo da Cerimônia foi marcado por conturbações devido às guerras e tentativas de unificação do país, por isso o mestre Rikyu trouxe para a Cerimônia características de simplicidade, observadas já inicialmente na Cabana de Chá (JHUN, 2012). O Ikebana, uma arte japonesa realizada com arranjos florais, também proporciona o sentimento de simplicidade manifestado por meio da estética, envolvendo o pensamento japonês quanto à natureza, ao belo e à espiritualidade (FREIRE, 2014) e compõe o conjunto que abrange a Cerimônia do Chá (HIROSE, 2010; JHUN, 2012). Posteriormente a Rikyu, alguns mestres o sucederam, até que surgiram algumas escolas próprias: Urasenke, Omotesenke e Mushanokojisenke, que estão em atividades até os dias atuais. Sen Soshitsu XV, o grande mestre Urasenke, que é a escola abordada nesse estudo, declarou que o propósito de preparação do ritual da Cerimônia do Chá é o de "perceber a tranquilidade da mente em comunhão com os semelhantes em nosso mundo" (ANDERSON, 1987, p. 475).

Por fim, para Bleiler (1963, p. 39), “a filosofia do chá não é mero esteticismo, no sentido usual da palavra, pois exprime, juntamente com a ética e a religião, nosso ponto de vista genérico acerca do homem e da natureza".

\subsection{A Cerimônia do Chá na comunidade nipo-brasileira}

A Cerimônia do Chá (Chanoyu), ao ter sua forma de celebração japonesa preservada pelos imigrantes japoneses no Brasil, contribuiu para o processo de adaptação desses no novo país, assim como um modo de articulação e integração com os brasileiros (ROCHA, 1998; JHUN, 2012). O Chanoyu representou um processo de adaptação étnica, estética e simbólica dos imigrantes japoneses, que buscaram em outros países uma forma de superar o período conturbado que o Japão enfrentava no século XIX, especificamente na Europa e na América, sendo o Brasil o principal destino da imigração japonesa. 
Rocha (1996) observa que a Cerimônia se transformou em uma forma de representar o ethos japonês pelos imigrantes e seus descendentes brasileiros, mantendo as tradições culturais. As práticas culturais e rituais da comunidade nipônica expressam cooperação do grupo envolvido, sendo essas ensinadas de geração para geração. É nesse sentido que, para Rocha (1999), a Cerimônia do Chá se tornou uma arte ideal para a transmissão de valores da cultura japonesa, sendo percebida como um verdadeiro símbolo do que é ser japonês, ao unir os ensinamentos de uma tradição, cultura e comportamento apropriado. Portanto, estudá-la ainda é altamente valorizado.

É na Cerimônia do Chá que os imigrantes japoneses e seus descendentes se agarram em sua tentativa de preservar sua identidade japonesa (IKARI, 2005). Eles a veem como o reservatório da tradição que deixaram para trás. Para os imigrantes japoneses e seus descendentes no Brasil, as aulas da Cerimônia do Chá eram uma ocasião social que oportunizava falar japonês, comer doces japoneses, ser japonês. Assim, a mesma proporciona sociabilidade e socialização e, por meio dela, os imigrantes e seus descendentes constroem sua identidade étnica.

Convém explicar que a prática da Cerimônia do Chá no Brasil passou a ser desenvolvida após a II Guerra Mundial (IKARI, 2005) e teve início em São Paulo a partir do IV Centenário, em 1954, evento que contribuiu para o incentivo da participação de comunidades de imigrantes, dentre essas, a comunidade japonesa (ROCHA, 1998; JHUN, 2012). As primeiras demonstrações da Cerimônia do Chá ocorreram e grupos de simpatizantes contribuíram para a fundação da Escola de Chá Urasenke e a fundação do Centro Urasenke do Brasil. Desde a realização das primeiras Cerimônias do Chá no Brasil já se passaram mais de 60 anos e, como esse ritual continua sendo realizado no país, alguns questionamentos chamaram a atenção: 1) Considerando que já se passaram mais de 100 anos do início da imigração japonesa para o Brasil, como esse ritual é realizado hoje e quais os componentes rituais que o compõem? E 2) os significados da cultura japonesa compartilhados na Cerimônia do Chá realizada na atualidade são os mesmos da década de 50 ou passaram por modificações? Quais as contribuições do consumo da Cerimônia do Chá? No intuito de encontrar respostas para esses questionamentos, foi realizada a presente pesquisa com o percurso metodológico conforme segue.

\section{Percurso Metodológico}

Partindo de uma abordagem qualitativa e descritiva (DENZIN; LINCOLN, 2006), buscou-se compreender os componentes rituais e os significados socioculturais do consumo da Cerimônia do Chá junto à comunidade japonesa no interior da Região Sul do Brasil. Tal região é caracterizada com expressiva participação cultural da população dos japoneses. Verificam-se 111 anos do início da imigração japonesa para o Brasil e que uma maior concentração de japoneses se encontra no sul e sudeste do País. O número estimado de cidadãos brasileiros com ascendência japonesa é de 1,5 milhão de pessoas, 
de acordo com o Consulado Geral do Japão em São Paulo (OLIVEIRA, 2017). De acordo com o Portal Bem Paraná (2018), o Paraná foi uma das unidades federativas que mais recebeu imigrantes japoneses e se beneficiou muito com a presença desta comunidade na sua construção.

Foram investigados os elementos constituintes da Cerimônia do Chá no que tange aos artefatos materiais, roteiro, papéis dos participantes, audiência e significados desse ritual.

A presente pesquisa contou com duas fases, uma exploratória na qual as pesquisadoras se aproximaram do tema e uma fase descritiva. Na primeira fase, foi realizada uma entrevista presencial com um mestre da Cerimônia de Chá e reunião de publicações que tratassem do tema. No segundo momento, com o intuito de buscar dados que contemplassem uma pesquisa descritiva, foi realizada observação participante e entrevistas com diversos atores envolvidos neste ritual.

A primeira fase trouxe informações que descreveram o cuidado que os japoneses têm ao escolher cada item da decoração que fará parte da Cerimônia do Chá, uma vez que cada um desses itens possui significados atrelados à cultura japonesa. Portanto, para a segunda fase, a coleta de dados por observação mostrou-se a mais indicada, para possibilitar a captação desses detalhes relevantes para o entendimento dos componentes rituais da Cerimônia do Chá. Também foi identificado na primeira fase que existem diferentes papéis dos participantes da Cerimônia, o que levou as pesquisadoras a optarem pela observação participante e, complementarmente, à coleta de dados com entrevistas pessoais que incluíssem diferentes agentes do ritual. As observações ocorreram durante um Festival de Cerimônia do Chá, em uma cidade localizada na Região Sul do Brasil. Foram entrevistados 10 participantes do Festival, com um roteiro previamente estruturado. Os entrevistados são todos da escola de chá Urasenke, como pode ser visto no Quadro 1, com uma breve caracterização e com seus respectivos nomes fictícios. Além disso, coleta de fotos, vídeos e artefatos (NIQUE; LADEIRA, 2014) foram realizadas a fim de contribuir para a análise e interpretação de informações.

Houve a preocupação de entrevistar tanto os convidados que participaram da Cerimônia do Chá, quanto os mestres e professores, visto que há diferença entre professor e mestre da Cerimônia. O professor ainda está se preparando para receber o título de mestre, que ocorre após aproximadamente vinte anos de estudos. O mestre é aquele que já possui o título e os anos de experiência da prática da Cerimônia. Já os convidados são aqueles que frequentam a Cerimônia como uma prática com ou sem interesse ou disponibilidade de dedicação aos estudos exigidos para com os professores e mestres. Além disso, não há uma distinção entre descendentes de japoneses, visto que o ensino e a aprendizagem da Cerimônia do Chá estão abertos a qualquer etnia. No caso das entrevistas realizadas, havia professores com média de quinze anos de experiência e aqueles já mestres. Por isso, as análises de ambos, mestres e professores, não foram distinguidas, mas apenas entre mestre/professor e convidados. 


\section{Quadro 1: Caracterização dos entrevistados}

\begin{tabular}{|c|c|c|c|c|}
\hline Entrevistado & Idade & $\begin{array}{l}\text { Tempo de } \\
\text { participação em } \\
\text { Cerimônias do Chá }\end{array}$ & $\begin{array}{l}\text { Descendência } \\
\text { japonesa }\end{array}$ & Papel no ritual \\
\hline Kimura & 41 & 30 anos & Sim & Mestre \\
\hline Robson & 50 & 19 anos & Não & Professor \\
\hline Marcelo & 55 & 36 anos & Não & Convidado principal \\
\hline Lívia & 26 & 10 anos & Sim & Convidado \\
\hline Silvia & 46 & 7 anos & Não & Convidado \\
\hline Roberto & 51 & 8 anos & Sim & Convidado \\
\hline Sandra & 53 & 15 anos & Sim & Convidado \\
\hline Mariana & 50 & 2 meses & Não & Convidado \\
\hline Camila & 25 & 1 ano & Sim & Convidado \\
\hline Lourdes & 60 & 45 anos & Sim & Convidado \\
\hline
\end{tabular}

Fonte: Autoras.

A respeito da análise dos dados, adotou-se a análise de conteúdo com ênfase nas operações de desmembramento do texto em unidades, chamadas categorias, segundo reagrupamentos analógicos, conhecida como análise categorial temática (BARDIN, 1977). Os temas emergiram da literatura consultada de Rook (2007), quanto aos elementos que compõem o ritual, e de Rocha (1996), quanto ao significado dos elementos da cultura japonesa. Quanto à operacionalização do método, foram utilizados a pré-análise, a exploração do material e o tratamento dos resultados, conforme exposto a seguir.

É digno de nota que o critério de triangulação foi adotado para assegurar a validade e confiabilidade da pesquisa. Seguindo o que é proposto por Denzin (2017) e Patton (1999), foi dada atenção à triangulação metodológica, por meio do uso de observação participante e entrevistas para investigar o mesmo fenômeno a partir de diferentes perspectivas. 


\section{Resultados e discussões}

\subsection{A Cerimônia do Chá e sentimentos evocados}

Todos os entrevistados, tanto os mestres e professores quanto os convidados, quando participaram pela primeira vez da Cerimônia do Chá, obtiveram conhecimento prévio da mesma devido às tradições ou contato com outras práticas da cultura japonesa. Essas tradições envolvem a tradição cultural, familiar e religiosa. Já aqueles que não têm descendência japonesa tiveram o primeiro contato com a Cerimônia do Chá por meio de outras práticas japonesas, tais como a prática da Ikebana.

A maioria dos entrevistados começou e continua participando da Cerimônia do Chá seguindo a tradição cultural e/ou tradição familiar, principalmente por incentivo dos pais, conforme o mestre Kimura demonstra: "Meu pai ensinava Cerimônia do Chá no Brasil e me incentivou a começar a estudar a Cerimônia [...]. Fui para Kyoto estudar a Cerimônia do Chá". Outros, ainda, justificam a participação como tradição religiosa, indicando a Igreja Messiânica como referência de influência de tradição.

Da mesma forma, há aqueles que participam da Cerimônia mesmo não sendo descendentes de japoneses, os quais conheceram a Cerimônia do Chá por curiosidade e interesse de estudo, assim como por praticar alguma outra atividade da tradição da cultura nipônica, como a Ikebana.

A celebração da Cerimônia evoca sentimentos compartilhados pelos participantes, tais como: satisfação em ensinar e servir, paz interior, alegria, honra e orgulho - são os mesmos, sem distinção entre convidados, mestres e professores. Esses sentimentos estão de acordo com os valores que a própria cultura nipônica estabeleceu como base, conforme apontado por Hirose (2010) e Anderson (1987). A satisfação em ensinar e servir, além de ser um dos significados da Cerimônia, é um sentimento proporcionado durante todo o momento da Cerimônia, em especial pelo mestre que a conduz. A maior preocupação no momento é com os participantes que estão ali para vivenciar aquele momento único. O mestre deve servir a todos com humildade e sem qualquer distinção. O ensinar está presente em todo o ritual, pois todos consideram que sempre há algo para aprender com o outro.

A paz interior é outro sentimento que vários entrevistados destacaram, principalmente pela atmosfera criada em torno de todo o ritual da Cerimônia do Chá. Esse é um dos propósitos do mestre da Cerimônia, buscando proporcionar um ambiente agradável e confortável a todos os presentes, de forma que os praticantes se sintam participando de um momento que é repleto de significados e que traz tranquilidade. Assim como a alegria, que advém do momento de celebração e partilha vivenciada por todos os presentes naquele momento, esse é um momento que muitos aproveitam para contemplar aspectos da cultura japonesa e resgatar memórias das gerações anteriores, proporcionando para a maioria sentimento de orgulho e honra por ter a oportunidade de estar presente na Cerimônia.

Convém mencionar que não são todos os entrevistados que frequentam ou frequentaram as Cerimônias somente na localidade de sua residência. Alguns já viajaram 
para participar da Cerimônia em grandes centros, no Japão, ou em cidades do interior do Brasil. Contudo, aqueles que já participaram da Cerimônia do Chá em diferentes locais destacam que não há diferenças de um local para o outro, sendo cada detalhe do ritual praticado da mesma forma, independente do mestre ou professor.

Diante disso, infere-se que a Cerimônia do Chá é repleta de significados culturais japoneses, distinguindo-a dos rituais e tradições compartilhados na sociedade brasileira como um todo.

\subsection{Significados da Cerimônia do Chá}

Os significados da Cerimônia do Chá são compartilhados pelos entrevistados, destacando que são esses significados que os cativam a continuar participando desse ritual. Esses significados são: expressar subserviência (ao ter a oportunidade de servir ao outro como um ato de valor de grupo, uma ação em prol da comunidade); qualificação pessoal, ao trocar experiências e aprender com os outros participantes; preservação de valores da tradição japonesa ( $\mathrm{Wa}, \mathrm{Kei}, \mathrm{Sei}$ e $J a k u$ ), ao resgatar lembranças das gerações anteriores.

Observa-se que os componentes simbólicos do ritual da Cerimônia do Chá transmitem o significado cultural da mesma, provocando a comunicação e categorização de um grupo de indivíduos (MCCRACKEN, 1986; 2007), compartilhando seus valores e significados (DOUGLAS; ISHERWOOD, 2004).

Identificou-se que a Cerimônia do Chá expressa de forma simbólica a harmonia perfeita vivenciada por meio da cultura japonesa. Por isso, é possível compreender por meio dos quatro valores da tradição japonesa os significados presentes na Cerimônia, ou seja, a harmonia $(\mathrm{Wa})$, o respeito $(\mathrm{Kei})$, a pureza $(\mathrm{Sei})$ e a tranquilidade $(\mathrm{Jaku})$.

A harmonia $(\mathrm{Wa})$ representa o equilíbrio e a paz entre o mestre ou professor e demais convidados, desde a organização do ambiente até os movimentos gestuais realizados durante o ritual. O respeito $(\mathrm{Kei})$ revela o ato de estar disposto a servir ao outro, escolhendo os objetos e artefatos especialmente para aquela Cerimônia e desejar aprender com o outro, trocando experiências e aprendizados. Assim, como representa um momento de resgatar e relembrar as gerações anteriores, seguindo exatamente suas tradições, como por exemplo, conversar no idioma japonês arcaico. Isso é uma forma concreta de relembrar as gerações anteriores, visto que esse era o idioma falado na época em que a Cerimônia do Chá foi regulamentada e passou a ser realizada no período das guerras que envolviam o Japão, conforme apontado por Hirose (2010).

A pureza $(\mathrm{Sei})$ remete aos gestos e ações realizados para purificar o ambiente e os artefatos utilizados, proporcionando a melhor qualidade para o chá no momento da Cerimônia. A tranquilidade ( $a k u)$, por sua vez, representa a condição básica para manter a concentração de forma a realizar a sequência correta dos gestos e ações durante a Cerimônia, especialmente do mestre e professor. 
Portanto, é possível inferir que a Cerimônia representa um momento de vivência de toda a cultura japonesa, cultuando seus valores e tradições, de forma a preservá-los. O ritual da Cerimônia proporciona a todos que dela participam a vivência dos quatro valores basilares da tradição japonesa. Esses valores são experienciados devido aos elementos que compõem a Cerimônia e que contribuem para a criação do ambiente harmônico propício para a sua realização, como demonstrado pelo professor Robson:

“Trazer a paz em uma xícara de chá. [...] existe essa ideia de fraternidade, buscamos harmonia (Wa). A primeira coisa que a gente busca no chá é harmonia. Harmonia com a gente, harmonia de gestos, harmonia entre as pessoas, os objetos. A segunda é Kei. Kei é respeito. Porque quando está tudo harmonizado você tem respeito. A terceira é Sei, que é limpeza, purificação. Porque se você tem harmonia e você tem respeito, você está limpo, está puro de coração. E a última é tranquilidade. Então, se você tem tudo isso, você chega na tranquilidade".

Observa-se, ainda, que cada Cerimônia do Chá, por mais que siga o roteiro de um ritual, proporciona momentos únicos de aprendizado e troca de experiências entre aqueles que estão presentes. As pessoas podem até serem as mesmas, porém a cada Cerimônia do Chá, cada pessoa traz consigo a experiência que viveu desde a sua última participação nesse ritual, o que implica na busca da vivência daquele momento de forma única, proporcionado pela paz transmitida por meio de uma tigela de chá.

Buscando compreender os significados da Cerimônia do Chá, atribui-se a ela os valores da tradição. A tradição, conforme apontado por Schwartz e Sagie (2000), abrange o respeito, o compromisso e a aceitação das ideias e costumes anteriormente estabelecidos, assim como preservação da tradição, que pode ser inferida a partir das entrevistas e observação realizadas. Além disso, é possível afirmar que os significados da Cerimônia permitem aos entrevistados categorizar suas experiências, atribuindo-lhes algum sentido, não sendo imanente aos objetos, mas também a eles atribuídos por quem os compreende e interpreta.

\subsection{Elementos que compõem o ritual da Cerimônia do Chá}

O ritual da Cerimônia do Chá segue um roteiro com seus significados e propósitos, primeiro elemento, segundo (ROOK, 2007), que compõe um ritual. Dentre as cerimônias observadas, destaca-se a atenção em cada gesto e manuseio dos artefatos utilizados, representando a harmonia. Sendo cada parte do ritual, com sua sequência estabelecida e construída a partir de uma simbologia. O esquema a seguir (Figura 1) representa a sequência de movimentos na Cerimônia. 


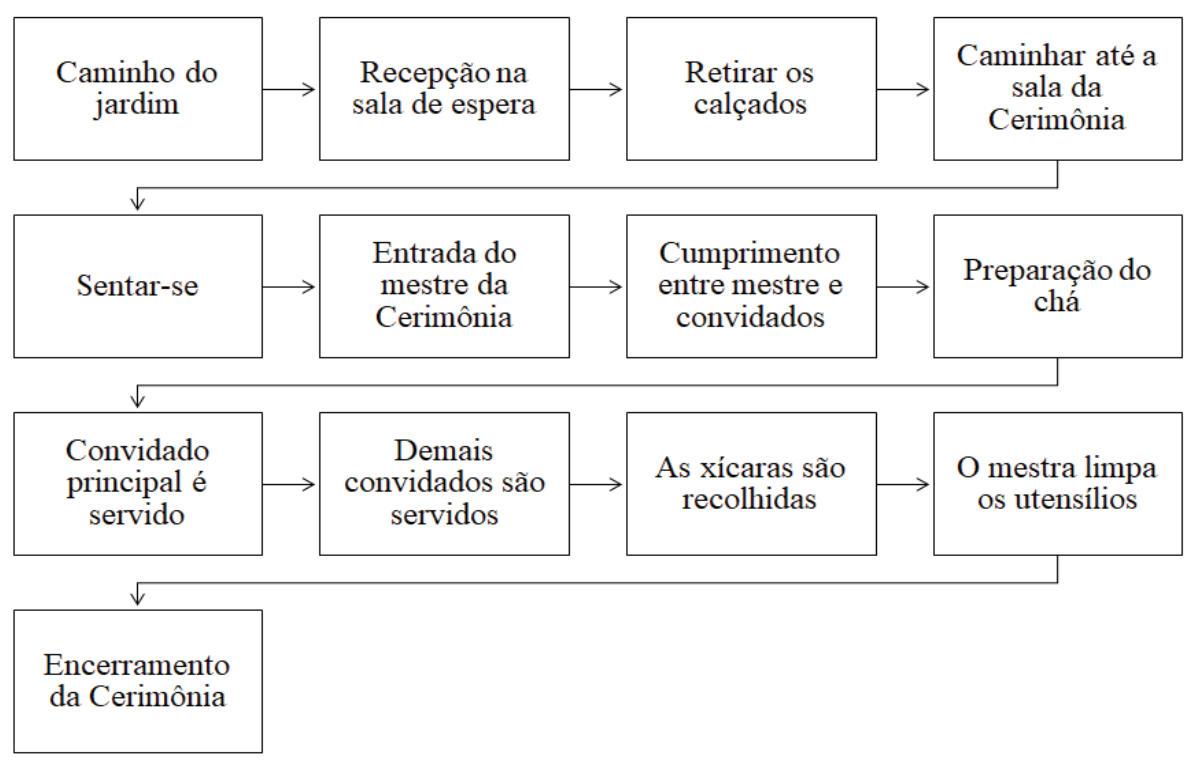

Figura 1. Esquema de movimento da Cerimônia do Chá Fonte: elaborado pelas autoras

Conforme exposto na Figura 1, há um percurso pelo jardim que conduz à Casa do Chá. A caminhada pelo jardim, conforme já assinalado por Rafacho (2007), é uma forma dos participantes buscarem a introspecção, para entrarem em um outro mundo e vivenciarem a cultura japonesa. Após caminhar, os convidados são recebidos com muita cortesia, em sinal de respeito para com o outro. Mesmo que em tom discreto, nota-se a satisfação em receber cada uma das pessoas que farão parte da Cerimônia. Todos os convidados precisam retirar os calçados e colocá-los em um armário alocado no canto da sala de espera. Tal prática remete a tradição japonesa de tirar os calçados quando entram em suas casas ou na casa de outra pessoa. Isso ocorre devido à questão de limpeza e higiene (física e espiritual). Em outras palavras, o ato de entrar com os pés descalços significa deixar para fora do ambiente da Cerimônia as energias negativas e as impurezas do exterior, contribuindo para manter a harmonia.

Na sequência, os convidados sentam-se no tatame ou nas cadeiras, variando da estrutura física de cada sala de chá. No entanto, o mais tradicional são as salas somente com o tatame. Questionados sobre essa diferença, os mestres da Cerimônia do Chá argumentaram que a mudança da estrutura ocorre para facilitar a acomodação daqueles que querem participar, mas possuem alguma debilidade física e não têm condições de ficarem de joelhos no tatame durante toda a Cerimônia, que tem duração média de quatro horas. Essa facilitação na acomodação possibilita que os idosos, principalmente, continuem a participar da Cerimônia, conforme tradição cultural dos mesmos.

Passando do roteiro para o segundo componente do ritual, os artefatos rituais (Rook, 2007), ressalta-se o significado do tatame, que conforme mencionado pelo Professor 
Robson, está presente na tradição japonesa e, principalmente, na Cerimônia do Chá desde o período milenar:

"Em relação ao tatame, o seu uso está associado a um pot-pourri de eventos históricos, culturais e sociais. Mas em resumo, ele era da época do ápice do chá, o assoalho de predileção nas construções, inclusive ele é a unidade de medida dos cômodos das casas. Aqui [no Brasil] se fala um quarto de 3x4 [metros], lá [no Japão] diríamos que a sala tem seis tatames. E daí, já sendo o chão oficial utilizado, sendo naturalmente imbuído de estética compatível ao gosto do chá e sendo hábito da época assentar-se diretamente no assoalho sem uso de mobília, foi natural que a prática do chá se adaptasse a ele da forma que é hoje. É muito estranho ver chá sem tatame apesar de não ser impossível, especialmente com a chegada de estrangeiros ao Japão na era Meiji e a criação de cerimônias em mesas para contemplar convidados não habituados a ficarem ajoelhados sobre suas próprias pernas".

Além do tatame, ao entrar na sala do chá, é possível observar a decoração e o ambiente criado para a realização da Cerimônia, proporcionando a todos os convidados tranquilidade e harmonia, assim como os valores basilares da tradição japonesa ( $\mathrm{Wa}, \mathrm{Kei}$, $S e i, J a k u$ ), que inclusive estavam escritos em um dos quadros de decoração de uma das salas (Figura 2). A decoração foi escolhida pelo mestre, considerando a estação do ano - a primavera. Assim como a atenção é dada em cada detalhe da decoração, a estação do ano também é considerada. Para os praticantes da Cerimônia, a harmonia com a estação do ano remete ao fato de desfrutar do momento como um todo, momento este que é único. O motivo da decoração acompanhar a estação do ano é explicado pelo professor Robson:

"Sendo o momento do agora tão raro e precioso, não é sábio desperdiçá-lo e para melhor desfrutá-lo, a melhor forma é a vivência em plena consciência desse momento. Não é fácil manter a mente desperta; a todo momento as correntezas do pensamento nos fazem nos perdermos em nós mesmos. Então, é preciso praticar a postura de estar de "corpo e alma" presente. Harmonizar a decoração à estação é uma prática que internaliza um conceito, o de estar atento no agora, nos mínimos detalhes que compõem o agora, e nos ajuda a aprender a viver em estado de mente atenta, condição essencial para desfrutar a vida na sua plenitude, viver, com $\mathrm{V}$ maiúsculo por assim dizer, o aqui e o agora".

Nas outras salas, havia vasos com desenhos de flores e arranjos florais, tradicionalmente da arte da Ikebana, conforme é possível visualizar no fundo da Figura 2. Tais arranjos eram contemplados pelos presentes na sala, que os compreendem como uma prática de dar vida às flores. Essa contemplação remete à apreciação da natureza por parte da tradição japonesa, assim como proporciona tranquilidade. É nesse sentido que Freire (2015) diz sobre a Ikebana ser uma forma de se libertar das tensões e agitações diárias, não só para aqueles que dão vida às flores, mas para aqueles que contemplam, como no caso dos participantes das Cerimônias observadas. 

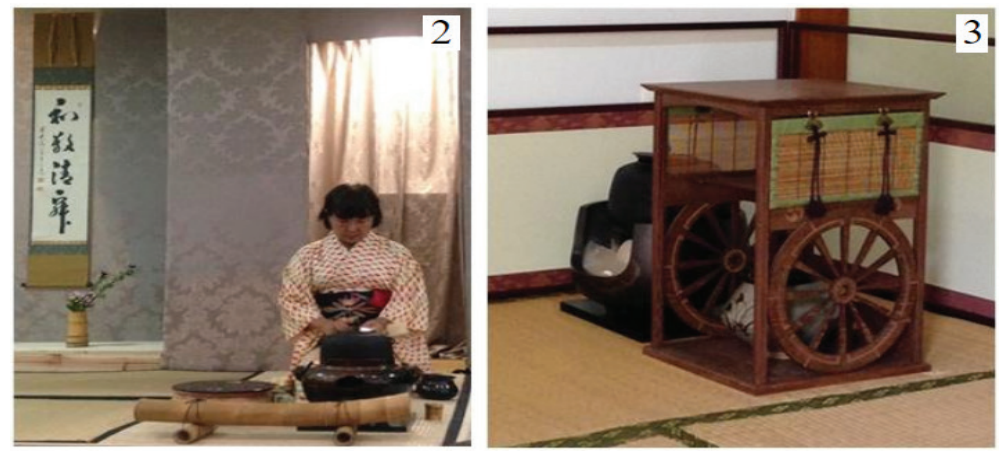

Figura 2. Mestre da Cerimônia do Chá preparando o chá e a decoração da sala com os valores $\mathrm{Wa}, \mathrm{Kei}, \mathrm{Sei}$, Jaku ao fundo.

Fonte: pesquisa empírica

Figura 3. Fogareiro, cerâmica e água para o chá.

Fonte: pesquisa empírica

As cortinas das salas foram escolhidas conforme a posição do Sol, que é influenciada pela estação do ano. Ainda, é possível notar que alguns artefatos utilizados para a Cerimônia já estavam organizados e preparados no canto da sala, tais como: a cerâmica, o fogareiro e a água para o chá (Figura 3). Todos os artefatos compõem o ritual, que, utilizados em conjunto, representam a harmonia no preparo do chá.

Após todos os convidados estarem organizados e sentados, seja no tatame ou nas cadeiras, é possível identificar o terceiro elemento que compõe os rituais, a representação dos papéis (ROOK, 2007). Neste momento, o mestre da Cerimônia entra na sala de chá, portando misturador e colher de bambu (chasen), colher de chá (chashaku) e a chaleira de água (Figura 4). Ele cumprimenta os convidados curvando-se e, dirige-se próximo ao fogareiro, para deixar os artefatos. O mestre sai da sala para trazer os demais artefatos, como: o suporte para a chaleira e uma colher, e o matcha, chá verde (Figura 5).
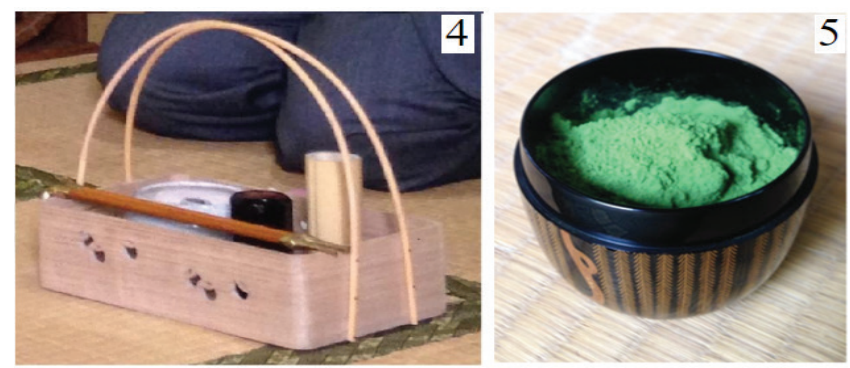

Figura 4. Chawan, xícara com chá, batedor, guardanapo, misturador e chashaku, espátula para o chá.

Fonte: pesquisa empírica

Figura 5. Matcha, o chá verde.

Fonte: pesquisa empírica 
O mestre estava trajado com o quimono, meias brancas e possuía um guardanapo de tecido, que foi possível ver depois, na hora de servir o chá. No mesmo sentido que Greiner (2015) menciona sobre o quimono, a veste observada em todas as Cerimônias carrega aspectos da tradição cultural dos antecedentes, principalmente seus aspectos simbólicos. Ao vestir o quimono para conduzir a Cerimônia, o mestre expõe sua capacitação para transmitir o saber. Os quimonos usados pelos mestres durante as Cerimônias observadas remetiam à subjetividade simbólica, da contemporaneidade pelas estampas modernas, mas que também apresentavam características tradicionais pelo modelo.

A preparação do chá ocorre da mesma forma, independente de qual mestre a esteja conduzindo. Em todas as cerimônias, foi possível observar os mesmos gestos e harmonia ao pegar um artefato ou dobrar um guardanapo. A preparação do chá inicia com a organização dos utensílios, seguida da purificação dos mesmos. Enquanto o mestre aquece a xícara para o chá a e o batedor do chá, todos os convidados são servidos com uma goma ou um doce típico japonês, com o objetivo de limpar as impurezas da boca. Essa goma é conhecida como kudzo, uma fécula extraída de uma planta de mesmo nome que é usada, por exemplo, para engrossar caldos e cremes. Segundo palavras do professor da Cerimônia, Robson, esse doce "confere um aspecto de frescor devido à consistência aquosa". Além disso, "o recheio usado é doce de favas brancas, outro componente muito presente nos doces usados no mundo do chá".

Vale ressaltar que durante toda a Cerimônia os convidados conversavam entre si. Os mais experientes explicavam para os novatos os significados da decoração ou o modo de se portar durante a Cerimônia, como os cumprimentos e os significados daquele momento.

Com o chá preparado, o primeiro convidado, sentado ao lado do mestre, é servido. E aqui é possível descrever o quarto e último elemento que compõe o ritual, que é a plateia (ROOK, 2007). Em seguida, o mesmo ocorre com os demais convidados. Conforme a tradição, a xícara de chá é entregue, precedida da genuflexão, tanto de quem serve e de quem é servido. Aquele que serve escolhe o lado mais bonito da xícara para entregar de frente para o convidado. Este último recebe-a e contempla o seu desenho ou caligrafia, tipicamente da tradição nipônica. Em seguida, toma o chá, apreciando-o até o último gole. Segundo a tradição, quando o convidado realmente gosta do chá, ele deve aspirar todo o restante que ainda estiver na xícara (chawan). Feito isso, a xícara é posta no tatame, com o lado mais bonito, conforme opinião do convidado, para frente. Assim, quando o mestre retirar a xícara, o mesmo a receberá com o lado mais bonito, em significado de respeito ao outro, também em condição de servi-lo.

Com todas as xícaras já retiradas, o mestre lava o batedor e a espátula, organizando os utensílios de forma a realocá-los do lado do batedor. Enquanto isso, os convidados continuam a conversa, as reflexões e as contemplações, principalmente acerca dos artefatos e objetos decorativos na sala de chá. Passado um breve período de tempo, a Cerimônia é encerrada pelo mestre e todos se retiram da sala. Os convidados voltam para a sala de espera e calçam seus calçados, enquanto o mestre vai para a cozinha guardar os artefatos. 
Diante de todas as observações, foi possível identificar os quatro elementos que compõem um ritual: artefatos, roteiro, representação dos papéis e plateia (ROOK, 1985; 2007). Os artefatos utilizados para a realização da Cerimônia são compostos por: recipiente para armazenar o chá (chaire), batedor de chá (chasen), espátula para o chá (chashaku), sala de chá (chashitsu), tigela para servir o chá (chawan), base de bambu para apoiar a concha (futaoki), concha para pegar água (hishaku), recipiente para esquentar água (kama), tigela para armazenar a água utilizada para limpeza, a ser descartada (kensui), recipiente para armazenar água fria (mizusashi), fogareiro (ro) e base do piso (tatame).

Cabe ressaltar que os artefatos carregam significados históricos e antropológicos. Aqueles construídos com bambu representam resistência quanto ao que diz respeito à força e ao vigor, conforme observado entre os mestres e convidados. Os artefatos de cerâmica, como a tigela, trazem consigo a influência da história da arte japonesa, sendo objetos pintados pelos próprios artistas japoneses. Por isso, a contemplação desse artefato e o cuidado ao tatear e devolver após beber todo o chá, por parte dos convidados. Por parte do mestre da Cerimônia, observou-se um processo de cuidadosamente orquestrar todos os elementos, conhecido como toriawase. Por meio desse processo, o mestre agrupa elementos específicos que contribuem para expressar uma mensagem simbólica, de acordo com a sua intenção.

Cabe ressaltar que, durante todas as observações, notou-se que mestre e convidados, principal e demais, são todos os atores que compõem o momento da Cerimônia do Chá. Todos esses possuem a mesma importância para aquele momento, independente da cultura, país de origem e hierarquia.

Por meio do estudo realizado, observou-se que a Cerimônia do Chá Japonesa é um ritual de troca (MCCRACKEN, 2007), visto que há constante busca do anfitrião em presentear os convidados com um momento único, que perpassa o cuidado com cada detalhe. No que diz respeito aos significados da Cerimônia do Chá no século XXI no Brasil, é possível depreender que esse ritual se mantém arraigado à tradição e aos significados originais que estão atrelados à harmonia $(\mathrm{Wa})$, ao respeito $(\mathrm{Ke} i)$, à pureza $(\mathrm{Sei})$ e à tranquilidade $(\mathrm{Jaku})$. Em outras palavras, o sentido e significados percebidos por meio da Cerimônia no século XXI continuam sendo os mesmos, ressaltando o interesse quanto ao resgate e manutenção da tradição milenar praticada pelas gerações anteriores, assim como contribuiu para o processo de imigração, no Brasil. Além disso, ficou evidente a influência da cultura japonesa no consumo de brasileiros não descendentes que participam da Cerimônia do Chá, especialmente por aqueles que buscam vivenciar a Cerimônia como mestres ou professores.

\section{Conclusão}

A tradição do ritual da Cerimônia do Chá segue rigorosamente os preceitos do regulamento estabelecido, no século XVI, por Sen-no-Rikyu (BOIKO, 2011), tal como 
os princípios do Centro de Chado Urasenke do Brasil. O ritual é tão fiel às tradições, conforme relato dos mestres, que chama a atenção de japoneses residentes no Japão. Estes últimos buscam no Brasil uma forma de tentar vivenciar como era a prática das tradições nipônicas no período milenar, antes das guerras.

A Cerimônia do Chá é considerada um catalisador da tradição cultural nipônica no Brasil, se não a maior é uma das expressões mais significativas das tradições japonesas resgatando memórias das gerações anteriores, uma vez que os nipônicos buscam até mesmo conversar no idioma japonês arcaico, tanto em respeito aos antepassados quanto como uma forma de preservar a cultura japonesa. Assim como adaptar a estrutura física da sala de chá, com cadeiras, para facilitar a participação daqueles que possuem dificuldades de se sentarem no tatame.

Observaram-se valores bastante arraigados à cultura japonesa, principalmente na contemplação dos artefatos provenientes do Japão. A casa de chá, onde ocorrem as Cerimônias e local de realização da presente pesquisa, é um exemplo. É uma reprodução de casa de chá fidedigna às do Japão, mesmo estando fora do país. A metragem, o tatame e a antessala foram construídos nos tamanhos padrões, assim como é no Japão, sendo construída com madeiras provenientes daquele país.

Como principais contribuições da Cerimônia, dois aspectos são destacados. O primeiro diz respeito aos imigrantes japoneses conseguirem preservar a sua cultura de forma enfática, não permitindo que a Cerimônia sofresse influência da cultura local e fosse descaracterizada. Ao contrário, foi observada a influência da cultura japonesa na cultura brasileira ao incluírem brasileiros não descendentes de japoneses no ritual da Cerimônia do Chá. Isso leva à preservação e difusão não só dos costumes em termos de ações como também de consumo de produtos. Falando especificamente da Cerimônia, há a influência dos descendentes japoneses sobre os brasileiros descendentes ou não de japoneses, em diversos consumos sendo eles na própria participação na Cerimônia, o consumo do chá japonês e dos artefatos da Cerimônia. Adicional a esse consumo, observou-se o deslocamento daqueles que vivem em cidades diferentes de onde as Cerimônias são realizadas. Para além da Cerimônia, destaca-se o consumo de alimentos típicos da tradição japonesa amplamente difundida na cultura brasileira. Para tanto, ressaltam-se a importância, para o mercado dos países de destino de imigração, de se conhecer a cultura dos imigrantes que podem influenciar o consumo de nativos.

$\mathrm{O}$ segundo ponto remete ao fato de que os rituais ajudam as sociedades a se organizarem, sendo intrínsecos às nações. O ritual da Cerimônia do Chá é um momento que proporciona ricas sensações e sentimentos em questão de espaço e tempo. A contemplação que envolve todos os artefatos, artes e decorações, avança além do visual, uma vez que outros sentidos são estimulados, como por exemplo o momento de saborear o próprio chá. O momento do ritual é considerado único, por isso a repetição da expressão "ichi-go, ichi-ê", que significa um encontro, um momento. Em outras palavras, é um momento que ocorre uma vez e nunca mais. Ao ser considerado único, esse momento é precioso. No caso da Cerimônia do Chá, pessoas conhecidas e desconhecidas encontram-se promovendo 
a integração e troca cultural entre as mesmas. Além disso, esta pesquisa contribui para o campo do trabalho acadêmico sobre Chanoyu.

Por fim, recomenda-se que as pesquisas futuras verifiquem se há diferenças no ritual, bem como no que se refere aos significados da Cerimônia do Chá entre outras escolas de chá, como Omotesenke e Mushanokojisenke.

\section{Referências}

A FESTA. História da Oktoberfest. Oktoberfest Blumenau. Disponível em: https://oktoberfestblumenau.com.br/a-festa/ Acesso: 13/11/2019.

ANDERSON, J. L. Japanese tea ritual: Religion in practice. Man, p. 475-498, 1987.

BARDIN, L. Análise de conteúdo. Lisboa: edições, v. 70, p. 225, 1977.

BLEILER, E. F. Introdução. In OKAKURA, O. (Eds.), O livro do chá. São Paulo: Pensamento, 1963, p. 9-26.

BOIKO, L. Breve história do chá no Japão. Disponível em < https://namakajiri.net/letras/2011/ historia_cha_japao.pdf $>$. Acesso:10/11/2019. São Paulo, 2011.

CASOTTI, L. M.; SUAREZ, M. C. Dez anos de Consumer Culture Theory: delimitações e aberturas. Revista de Administração de Empresas, v. 56, n. 3, p. 353-359, 2016.

CUPOLILLO, M. B. N.; CASOTTI, L. M.; CAMPOS, R. D. Estudos de consumo: um convite para a riqueza e para a simplicidade da pesquisa de rituais brasileiros. Revista ADM. MADE, v. 17, n. 3, p. 27-46, 2014.

DENZIN, N. K.; LINCOLN, Y. S. O planejamento da pesquisa qualitativa: teorias e abordagens. In: O planejamento da pesquisa qualitativa: teorias e abordagens. 2006.

DENZIN, N. K. The research act: A theoretical introduction to sociological methods. Routledge, 2017.

DOUGLAS, M.; ISHERWOOD, B. O mundo dos bens: para uma antropologia do consumo. Rio de Janeiro: UFRJ, 2004.

FREIRE, A. B. A arte japonesa e a Ikebana na produção de Toshiro Kawase. 2014. Tese de Doutorado. Universidade de São Paulo.

GOLDSTEIN-GIDONI, Ofra. The production and consumption of 'Japanese culture'in the global cultural market. Journal of consumer culture, v. 5, n. 2, p. 155-179, 2005.

GREINER, C. Leituras do Corpo no Japão e suas diásporas cognitivas. 2015. Tese de Doutorado. São Paulo: PUC.

HIROSE, C. A experiência do corpo na cerimônia do chá-subsídios para pensar a educação. 2010. Tese de Doutorado. Universidade de São Paulo.

HOFSTEDE, G. Cultures and Organizations: Software of the Mind. McGraw-Hill, New York, NY, 1997. 
IKARI, L. T. Lazer do imigrante japonês no Brasil. Estudos japoneses, n. 25, p. 71-80, 2005.

JHUN, S. S. Y. A Cerimônia do Chá como elemento de convivialidade na população nipo-brasileira. 2012.Dissertação de Mestrado. Universidade Anhembi Morumbi, São Paulo.

LEVY, S. J. Symbols for sale. Harvard Business Review, p. 203-212, 1959.

LIMA, G. Início da Oktoberfest tem aumento de público de 74\% neste ano. NSC Total Capa Caderno Entretenimento, 2019. Disponível em https:/www.nsctotal.com.br/noticias/inicio-da-oktoberfest-tem-aumento-de-publico-de-47-neste-ano. Acesso em 13/11/2019.

LUNA, D.; GUPTA, S. An integrative framework for cross-cultural consumer behavior. International marketing review, v. 18, n. 1, p. 45-69, 2001.

MCCRACKEN, G. Culture and consumption: A theoretical account of the structure and movement of the cultural meaning of consumer goods. Journal of consumer research, v. 13, n. 1, p. 71-84, 1986.

MCCRACKEN, G. Cultura \& consumo. Mauad Editora Ltda, 2003.

MCCRACKEN, G. Cultura e consumo: uma explicação teórica da estrutura e do movimento do significado cultural dos bens de consumo. Revista de Administração de Empresas, v. 47, n. 1, p. 99-115, 2007.

NIQUE, W.; LADEIRA, W. Pesquisa de marketing: uma orientação para o mercado brasileiro. São Paulo: Atlas, 2014.

OLIVEIRA, N. O Japão dentro do Brasil. Disponível em: <http://www.turismo.gov.br/\%C3\%BAltimas-not\%C3\%ADcias/7896-o-jap\%C3\%A3o-dentro-do-brasil.html $>$ Acesso em: 26/11/2019. Brasília, 2017.

PATTON, M. Q. Enhancing the quality and credibility of qualitative analysis. Health services research, v. 34, n. 5 Pt 2, p. 1189, 1999.

PORTAL BEM PARANÁ. Paraná se prepara para os 110 anos da imigração japonesa. Disponível em: <https:/www.bemparana.com.br/noticia/parana-se-prepara-para-os-110-anos-da-imigracao-japonesa\#.Xd0srVdKjIV> Acesso em: 26/11/2019. Paraná, 2018.

RAFACHO, A. M. O jardim do chá um caminho para a iluminação. Estudos Japoneses, v. 27, p. 51-60, 2007.

ROCHA, C. M. A Cerimônia do Chá no Japão e sua reapropiação no Brasil: uma metáfora da identidade cultural do japonês. 1996. Dissertação de Mestrado. São Paulo: USP.

ROCHA, C. M. A Cerimônia do Chá como fator de identidade cultural para imigrantes japoneses e seus descendentes no Brasil. Estudos Japoneses, n. 18, p. 39-48, 1998.

ROCHA, C. M. Identity and tea ceremony in Brazil. Japanese Studies, v. 19, n. 3, p. 287-295, 1999.

ROOK, D. W.; LEVY, S. J. Psychosocial themes in consumer grooming rituals. Brands, Consumers, Symbols and Research: Sidney J Levy on Marketing, v. 375, p. 21-43, 1983. 
ROOK, D. W. The ritual dimension of consumer behavior. Journal of consumer research, v. 12, n. 3, p. 251-264, 1985.

ROOK, D. W. Dimensão ritual do comportamento de consumo. Revista de Administração de Empresas, v. 47, n. 1, p. 81-98, 2007.

SCHWARTZ, S. H.; SAGIE, G. Value consensus and importance: A cross-national study. Journal of cross-cultural psychology, v. 31, n. 4, p. 465-497, 2000.

SOLOMON, M. R. O Comportamento do consumidor - comprando, possuindo e sendo. Bookman Editora, 2011.

Turner, V. W. (1974). O processo ritual: estrutura e antiestrutura. Petrópolis: Vozes.

VAN GENNEP, A. Os ritos de passagem. Petrópolis: Vozes, 1978. 